World Journal of Applied Economics (2020), 6(1): 91-98

doi: $10.22440 /$ wjae.6.1.6

econworld

Brief Article

\title{
Inequalities and Unfair Income Distribution in
} Japan

\author{
SAYAKA SAKODA \\ Received: 12.10.2019; Revised: 26.02.2020; Accepted: 06.04.2020
}

\begin{abstract}
There has been a debate about what measurement is most appropriate for measuring inequality because the classical index does not distinguish between what is fair and unfair distribution of income. In this empirical study, the "Responsibility-Sensitive Egalitarian Theory" is applied for the case of Japan. Our paper firstly tracks the historical evolution of inequalities and concludes that the Japanese accept pre-tax income inequality because they believe their socio-economic class is determined by luck. Secondly, illustrating the Unfairness Lorenz Curve by gender shows that females face more unfairness than males: the pre-tax income of middle-income males increases slightly compared to the fair-income group from 2010 to 2013. However, the opposite is true for females in the bottom and middle classes. Considering there already exists a gender wage gap in Japan, it is necessary to take action to reduce inequality.
\end{abstract}

JEL codes: D31, D63, J31

Keywords: Income inequality, Fairness, Responsibility-Sensitive Egalitarian Theory.

\section{Introduction}

The question of what kind of index to use to measure income inequality has been debated. In conventional analysis, empirical economists have been interested in actual income inequality. Often-used classical indexes, for example, the Gini coefficient or Lorenz curve, that measure inequality assume implicitly that any deviation from the average income is considered unfair as the measures use the equal income distribution as a reference point for measurement. There is growing concern about what should be considered a fair distribution of income in a society. The standard approaches for measuring income inequality and distribution of income do not properly distinguish between fair and unfair inequality.

In general, we can regard inequality stemming from factors under the control of individuals (e.g. hours spent working) as fair, while inequality caused by factors that are beyond the control of the individuals (e.g. race or gender) are seen as unfair. This assumption is based on a fundamental moral ideal in Western societies that people should be held personally responsible for the consequences of their choices (Greenfield, 2011). After the 1990s, French sociologist, Rosanvallon (1995), pointed out that the trend of emphasizing self-responsibility rather than mutual help has grown all over the world.

a Japan Society for the Promotion of Science, Kyoto University, Kyoto, Japan. e-mail: ssakoda0715@gmail.com. (D) https://orcid.org/0000-0002-4239-9596 
Mirrlees (1971) sets out a framework in which the ideal of egalitarianism in outcomes can be reconciled with incentive constraints. Researchers, especially in the field of philosophy have confronted this problem. "Egalitarian Liberalism" by Dworkin (1981a,b), Arneson (1989) and Cohen (1989) is one example. The idea is to eliminate the impact of luck or misfortune and differences in natural and social circumstances on each person's welfare. One's view as to fairness depends upon whether the cause of inequality is caused by "luck" that is unavoidable for the person concerned or is the result of "choice". As above-mentioned Greenfield (2011) points out, if it is an outcome of one's "choice," the person should be responsible for his/her consequences, whereas inequality caused by environmental factors should be compensated. This idea is called "Responsibility-sensitive egalitarian theory" $(R S E)$, which supports the claim that inequalities resulting from people's choices are acceptable. A person's choice entails his or her responsibility for the choice's consequences. Dworkin $(2002,323)$ advocates $R S E$ by claiming that "it aims to make people's impersonal resources sensitive to their choices but insensitive to their circumstances". In this respect, $R S E$ decomposes each labour income into "circumstance" and "effort".

This paper attempts to (i) track the historical evolution of inequalities by using subjective and objective measures in order to specify the factors that determine whether inequality is fair or unfair, and (ii) measure and illustrate unfair income distribution in Japan.

The remainder of this paper is as follows. Section 2 explains the historical evolution of inequalities in Japan. Section 3 gives the employed method for empirical estimation. Lastly, Section 4 presents the policy implications, conclusion, and a vision for further research.

\section{The Historical Evolution of Inequalities in Japan}

The topic of inequality and redistribution has been debated also in Japan.

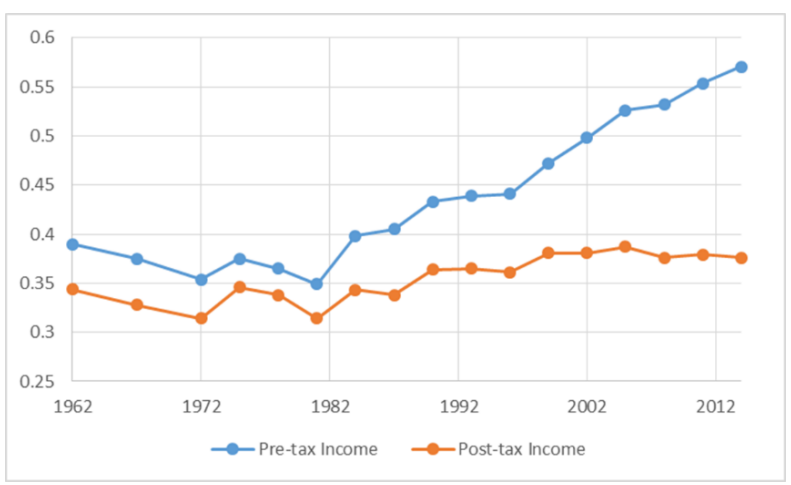

Figure 1: The transition of Japanese pre- and post-tax income Gini coefficient Source: Survey on the Redistribution of Income 1962-2014, Ministry of Health, Labour and Welfare

As shown in Figure 1, post-tax Gini has been more stable over the last 50 years, whereas pre-tax Gini has been rising after 1980. It shows Japanese redistribution policy has succeeded to suppress post-tax inequality.

Table 1 shows the percentage of longitudinal data detailing the transition of status identification from several waves of "The Public Opinion Survey on the Life of the People" conducted by the Public Relations Office and Cabinet Office. The survey measures people's satisfaction with their present lives over a long period of time. Status identification is a 
subjective evaluation of one's own social status in society. This is measured by the responses to the question "Compared to the general public, what do you think is the standard of living for your household?". The response options are Upper class, Upper middle class, Lower middle class, Working class, and Lower class.

Table 1: Longitudinal Transition of Status Identification and Pre-Tax Gini Coefficient.

\begin{tabular}{lrrrrrrrrr}
\hline$(\%)$ & 1935 & 1945 & 1955 & 1965 & 1975 & 1985 & 1995 & 2005 & 2010 \\
\hline Upper class & 2.1 & 0.7 & 0.2 & 0.3 & 1.2 & 1.9 & 1.4 & 0.6 & 0.9 \\
Upper middle class & 18.5 & 10.6 & 7.1 & 12.1 & 23.4 & 24.0 & 25.5 & 16.8 & 23.8 \\
Lower middle class & 32.2 & 28.8 & 34.8 & 42.7 & 53.0 & 47.4 & 46.8 & 38.4 & 47.7 \\
Working class & 26.9 & 32.3 & 37.7 & 32.2 & 16.7 & 17.5 & 15.9 & 25.5 & 18.9 \\
Lower class & 16.3 & 25.2 & 18.6 & 8.8 & 3.9 & 5.9 & 5.8 & 7.7 & 5.8 \\
Don't Know & 3.9 & 2.3 & 1.6 & 3.9 & 1.8 & 3.3 & 4.7 & 11.0 & 2.8 \\
\hline Sample size & 1,232 & 1,232 & 2,014 & 2,077 & 2,724 & 2,473 & 2,490 & 2,660 & 772 \\
\hline Pre-tax income Gini & 0.451 & 0.641 & 0.298 & 0.299 & 0.375 & 0.375 & 0.441 & 0.526 & 0.554 \\
\hline \multicolumn{5}{l}{ Source: Pre-tax Gini till } & 1985 is retrieved from Otsuki \& Takamatsu (1978) and Mizoguchi (1974).
\end{tabular}

According to the table, actual income inequality measured by pre-tax Gini coefficient does not always correspond with class self-identity. More precisely, through the 1950s and 1960s, the percentage of "Working class + Lower class" decreased and the percentage of "Lower middle + Upper middle class" increased. Eventually, in the late 1970s and early 1980s, around 90 percent of Japanese proudly identified themselves as middle class, though there were still remained socio-economic inequality and poverty in the society. Between the post-World War II era (1954) and the end of the Cold War (1991), Japan achieved the socalled Japanese economic miracle, which brought about the "Japanese-are-all-middle-class" mentality to the Japanese society. After the bubble collapse in the late 1990s until when the pre-tax Gini exceeded 0.5 in 2009, most of the respondents answered that they are originally from the middle class. ${ }^{1}$ On the other hand, the majority still believed they are in the middle class and a few people regard themselves as belonging to a higher class.

Considering the information in Figure 1 and Table 1, one can see the widening gap between pre- and post-tax income has been taking place since the 1980s. It implies that, even though income inequality increased from the mid-2000s, self-identification has not changed. From this point of view, Japan's income redistribution policy has been succeeded in suppressing actual post-tax inequality and self-identification. If the reference point is post-tax income, it significantly reduces the Gini coefficient of initial income and does not change status identification. The same tendency is also retrieved from the results of the International Social Survey Programme (hereafter, ISSP-2009), which compared the original and current status identification and found no significant change in the response to the question "which social class would you say you belong to?" These results indicate that the Japanese accept pre-tax income inequality.

According to the results of Hashimoto (2018) by using "The National Survey of Social Stratification and Social Mobility", inequality has been accepted among the poor by the results of the response of question "I accept if the gap between the rich and poor is getting wider" between 2005 and 2015. This also explains that the tendency to accept inequality is not based on the change of self-identity distribution, but rather on the change of objective

${ }^{1}$ In Japan, a greatly inflated bubble in real estate and stock market prices occurred between 1986 and 1991. in early 1992, the price bubble burst and the economy stagnated. 
social status and how it impacts people's self-evaluation. This tendency may reflect the perceived causes of inequality such as whether their current social-economic class is determined by luck or by effort.

\section{Empirical Literature}

In the previous section, it is explained that the "all-Japanese-are-middle-class" mentality has remained because people consider their current social-economic class as determined by luck or effort. This section measures the unfair Gini coefficient using RSE.

Following the afore-mentioned philosophical studies, Betts \& Roemer (1999), Page \& Roemer (2001), Roemer (1993), Bourguignon et al. (2007), Cappelen \& Tungodden (2007) and Devooght (2008), among others, are some examples of empirical studies. Almås et al. (2011) has two objectives: (1) identifying the fair distribution of income by using a general framework developed by Cappelen \& Tungodden (2007) which considers the distinction between fair and unfair inequalities; and (2) proposing the unfairness Lorenz curve and Gini coefficients to clarify the fair inequality in Norway from 1986 to 2005. The authors find that pre-tax income distribution has become unfair when the classical Gini has decreased in the same period, and post-tax income distribution has become unfair as well due to the tax system.

This paper continues the work of the Cappelen \& Tungodden (2007) by measuring economic unfairness. It is assumed that pre-tax income, $y_{i}$, consists of a function of the responsibility $\left(x_{i}^{R}\right)$ and non-responsibility $\left(x_{i}^{N R}\right)$ characteristics of each individual $i$ as follows.

$$
y_{i}=f\left(x_{i}^{R}, x_{i}^{N R}\right)
$$

The environmental variable that cannot be attributed to the person's responsibility is represented by $x_{i}^{N R}$ (environmental variables); the effort variable that can be attributed to the person's responsibility is represented by $x_{i}^{R}$ (effort variables), and the unobservable determinant is represented by $v_{i}$ and $u_{i}$. At this time, the labour income function can be described as in equation (2). According to $R S E$, effort variables are affected by environmental variables. $u_{i}$ is an error term.

$$
\text { wage }_{i}=f\left(x_{i}^{N R}, x_{i}^{R}\left(x_{i}^{N R}, v_{i}\right), u_{i}\right) .
$$

According to the definition used by Bourguignon et al. (2007), $x_{i}^{N R}$ is composed of five variables: two variables regarding the parents' education level: (1) the average of a parent's education level $(M P E)$ and (2) the difference between a parent's education level $(D P E)$, (3) race $(R)$, (4) place of birth $(G R)$, and (5) father's occupation $(F O) \cdot x_{i}^{R}$, on the contrary, is composed of (1) personal education level $(S)$, (2) an immigration dummy variable $(M)$, and (3) employment status $(L)$.

The relative income claim, $g\left(X_{i} ;.\right)$, is based on personal responsibility as shown in equation (3).

$$
g\left(x_{i}^{R} ; .\right)=\frac{1}{n} \sum_{j} f\left(x_{i}^{R}, x_{i}^{N R}\right)
$$

where $\mathrm{n}$ is the total number of observations, and subscripts $i$ and $j$ indicates that the variable belongs to individual $i$ and $j$, respectively. For individual $i, g\left(x_{i}^{R}\right)$ is composed only of $x_{i}^{R}$. 
Thus, the difference between the current pre-tax income $\left(y_{i}\right)$ and the fair income, $z_{i}$, can be expressed as follows.

$$
d_{i} \equiv y_{i}-z_{i}
$$

In this setup, $d_{i}$ illustrates the Lorenz curve based on fair income (hereafter, written as Unfairness Lorenz Curve). Unfairness Lorenz Curve graphs the differences cumulatively from smallest to largest. It allows for a distinction between responsibility and nonresponsibility income variables to determine the implications of a $R S E$.

$$
L(s ; A)=\frac{\sum_{i=1}^{n s} d_{i}}{n \mu(A)}
$$

where $0 \leq s \leq 1$. What is impressive is that $R S E$ itself does not consider gender. However, it is well known that there is gender wage gap: OECD (2017) reports that Japan had a gender wage gap of 25.7 percent in 2017, which was the third-highest wage gap among the OECD countries. This paper, therefore, extends RSE to show the result of the Unfairness Lorenz Curve by gender.

\begin{tabular}{|c|c|c|c|c|c|c|}
\hline & \multicolumn{6}{|c|}{ Male } \\
\hline & \multicolumn{3}{|c|}{ Middle education } & \multicolumn{3}{|c|}{ Higher education } \\
\hline & Obs. & Mean & Std. Dev. & Obs & Mean & Std. Dev. \\
\hline Parental education (MPE) & 1030 & 3.736 & 3.989 & 1638 & 4.208 & 3.429 \\
\hline Parental education (DPE) & 1030 & 0.739 & 3.244 & 1638 & 1.723 & 3.815 \\
\hline Place of birth (GR) & 1048 & 2.637 & 1.067 & 1645 & 2.401 & 1.081 \\
\hline Father's occupation (FO) & 1048 & 6.124 & 4.630 & 1645 & 4.449 & 3.779 \\
\hline Employment status (L) & 1048 & 6.424 & 4.216 & 1645 & 5.352 & 4.114 \\
\hline Working hours & 753 & 6.466 & 1.335 & 1296 & 6.590 & 1.205 \\
\hline \multirow[t]{4}{*}{ Age } & 1048 & 54.035 & 13.350 & 1645 & 53.066 & 13.230 \\
\hline & \multicolumn{6}{|c|}{ Female } \\
\hline & \multicolumn{3}{|c|}{ Middle education } & \multicolumn{3}{|c|}{ Higher education } \\
\hline & Obs. & Mean & Std. Dev. & Obs & Mean & Std. Dev. \\
\hline Parental education (MPE) & 1046 & 3.853 & 3.654 & 563 & 5.055 & 3.375 \\
\hline Parental education (DPE) & 1046 & 1.141 & 3.547 & 563 & 2.092 & 3.721 \\
\hline Place of birth (GR) & 1061 & 2.454 & 1.113 & 565 & 2.322 & 1.073 \\
\hline Father's occupation (FO) & 1061 & 5.263 & 4.372 & 565 & 4.211 & 3.663 \\
\hline Employment status (L) & 1061 & 8.363 & 3.803 & 565 & 7.616 & 4.041 \\
\hline Working hours & 558 & 5.582 & 1.537 & 341 & 5.930 & 1.468 \\
\hline Age & 1061 & 48.830 & 12.627 & 565 & 44.046 & 12.662 \\
\hline
\end{tabular}

Table 2: Descriptive Statistics

Doshisha University conducted a survey on "Life and Happiness in Regional Areas" from 2010 to $2013 . .^{2}$ The resulting panel data includes information on household income, consumption, work, educational attainment and parental educational attainment. The number of households covered in the latest wave of the survey in 2013 was 3,206. Table 2 shows the descriptive statistics of the variables used by gender and education level $(S)$. Used variables are $M P E, D P E, G R, F O, S, L$. The race $(R)$ and immigration $(M)$ variables are omitted because the population of Japan is $98.5 \%$ Japanese.

2 The design of the questionnaire was made by the author. This data was used because there is not much data available to make use of the socio-economic background of respondents and their parents. 
The difference by gender can be seen from both the shape and the depth of the curves in Figure 2 and 3, which measures unfairness.

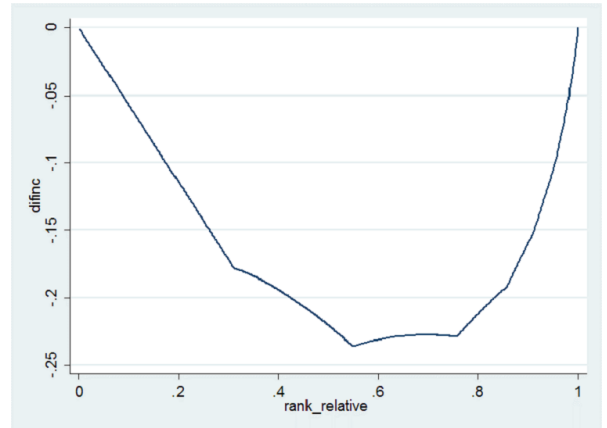

(a) Female

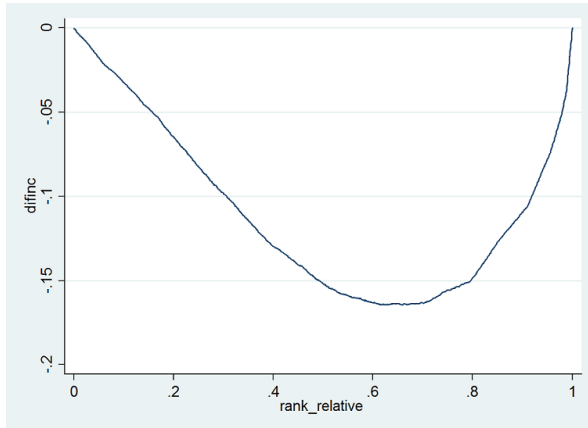

(b) Male

Figure 2: Unfairness Lorenz Curve, 2010

The fact that the female's curve is not smooth may be due to the "Spouse Tax Exemption." It is a special exemption for spouses to reduce the tax burden by deducting a fixed amount from the income tax imposed on taxpayers who have a dependent spouse. ${ }^{3}$

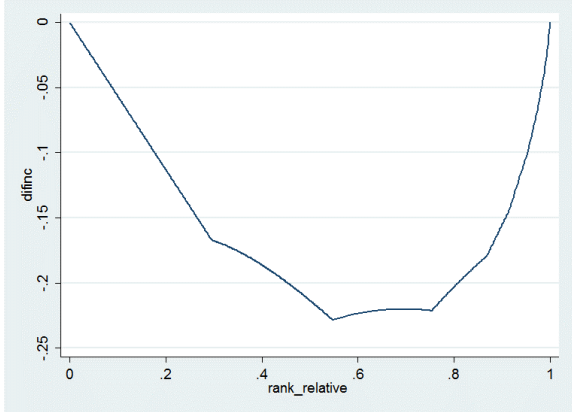

(a) Female

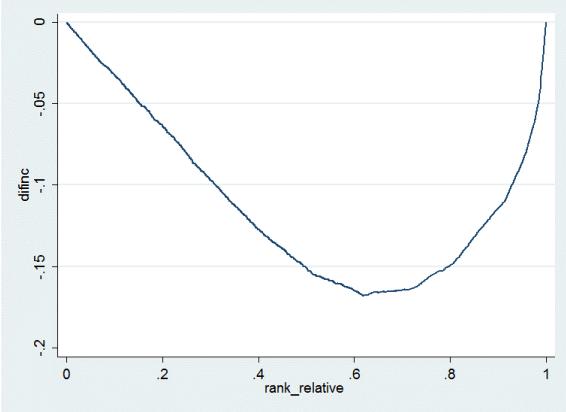

(b) Male

Figure 3: Unfairness Lorenz Curve, 2013

By reviewing the depth of the curve, firstly it can be concluded that perceived unfairness among females is more serious than among males. Secondly, the middle of the curve indicates that the distance between the pre-tax income and the fair income slightly decreased for males in the middle-class group in 2013, compared to 2010. The opposite is the case for females in the bottom and the middle class. In the context of existing literature illustrating the Unfairness Lorenz Curve (e.g. Stavem \& Støren, 2016; Hufe et al., 2018), Japanese female appear to face unfairness and inequality.

${ }^{3}$ For eligible couples, the upper limit on the annual salary income of the spouse was increased from 1.03 million Yen to 1.5 million Yen in 2016. This means 380,000 Yen exemption from the wage tax income. 


\section{Conclusion and a vision for further research}

This manuscript explores unfairness inequality based on the roots in the work of philosophical theory "Responsibility-Sensitive Egalitarian Theory" $(R S E)$ by following Dworkin (1981a,b), Anderson (1999) and Cohen (1989).

This paper measures economic unfairness by using the theory of $R S E$ applied to data collected in Japan from 2010 to 2013. The aims of the paper are (1) tracking the historical evolution of inequalities and (2) measuring and illustrating income inequalities in Japan by gender.

This paper firstly tracks the historical evolution of inequalities by comparing pre-tax Gini and status identification. While there has been a widening socio-economic gap in Japan, the "Japanese-are-all-middle-class" mentality is still prevalent. This is due to how people consider whether their current social-economic class is determined by luck or effort, which is indicated by the ISSP-2009.

Secondly, by using the model developed by Cappelen \& Tungodden (2007) and Almås et al. (2011) this paper illustrates the Unfairness Lorenz Curve by gender. We observe that females face more unfairness than males. The pre-tax income of middle-class males slightly decreased its distance to the group's fair income in 2013 compared to 2010, whereas the opposite is the case for females in the bottom and the middle class.

As previously mentioned, OECD (2017) reveals that there were still remains a gender wage gap in Japan. Given the gender wage gap, a policy to reduce inequality may inadvertently lead to incorrect labour policy.

Anderson (1999) developed "Anderson's criticism, the harshness objection" to criticize $R S E$ because it holds strictly to the notion that there are consequences tied to responsibility. There exist youth who chose to work for their families despite their educational opportunities, women who quit their jobs for the family, and the middle-aged males or females who leave their job to care for their sick/ageing family member. Understanding these perspectives is required for considering how to best reduce inequality.

\section{References}

Almås, I., Cappelen, A. W., Lind, J. T., Sørensen, E. ., \& Tungodden, B. (2011). Measuring Unfair (in) Equality. Journal of Public Economics, 95(7-8), 488-99. doi:10.1016/j.jpubeco.2010.11.002

Anderson, E. S. (1999). What is the Point of Equality? Ethics, 109(2), 287-337. doi:10.1086/233897

Arneson, R. J. (1989). Equality and Equal Opportunity for Welfare. Philosophical Studies, 56(1), 77-93. doi:10.1007/BF00646210

Betts, J. R., \& Roemer, J. E. (1999). Equalizing Educational Opportunity Through Educational Finance Reform (Working Papers No. 118). University of California, Davis, Department of Economics.

Bourguignon, F., Ferreira, F. H., \& Menéndez, M. (2007). Inequality of Opportunity in Brazil. Review of Income and Wealth, 53(4), 585-618. doi:10.1111/j.14754991.2007.00247.x 
Cappelen, A. W., \& Tungodden, B. (2007). Local Autonomy and Interregional Equality. Social Choice and Welfare, 28(3), 443-60. doi:10.1007/s00355-006-0183-2

Cohen, G. A. (1989). On the Currency of Egalitarian Justice. Ethics, 99(4), 906-44. doi:10.1086/293126

Devooght, K. (2008). To Each the Same and to Each his Own: A Proposal to Measure Responsibility-Sensitive Income Inequality. Economica, 75(298), 280-95. doi:10.1111/j.1468-0335.2007.00602.x

Dworkin, R. (1981a). What Is Equality? Part 1: Equality of Welfare. Philosophy \& Public Affairs, 10(3), 185-246.

Dworkin, R. (1981b). What Is Equality? Part 2: Equality of Resources. Philosophy \& Public Affairs, 10(4), 283-345.

Dworkin, R. (2002). Sovereign Virtue: The Theory and Practice of Equality. Harvard University Press.

Greenfield, K. (2011). The Myth of Choice: Personal Responsibility in a World of Limits. Yale University Press.

Hashimoto, K. (2018). Social Class in Japan (in Japanese). Kodansha-Gendai-Shinsyo.

Hufe, P., Kanbur, R., \& Peichl, A. (2018). Measuring Unfair Inequality. https://voxeu .org/article/measuring-unfair-inequality.

Mirrlees, J. A. (1971). An Exploration in the Theory of Optimum Income Taxation. The Review of Economic Studies, 38(2), 175-208. doi:10.2307/2296779

Mizoguchi, T. (1974). Income and Assets Distributions in Post-war Japan (in Japanese). Economic Review, 25(4), 345-66. doi:10.15057/23750

OECD. (2017). The Pursuit of Gender Equality. doi:10.1787/9789264281318-en

Otsuki, T., \& Takamatsu, N. (1978). An Aspect of the Size Distribution of Income in Prewar Japan (Discussion Papers No. 9). International Development Center of Japan.

Page, M., \& Roemer, J. E. (2001). The U.S. fiscal System as an Opportunity-Equalizing Device. In K. A. Hassett \& R. G. Hubbard (Eds.), Inequality and Tax Policy (pp. 134-65). The American Enterprise Institute Press.

Roemer, J. E. (1993). A Pragmatic Theory of Responsibility for the Egalitarian Planner. Philosophy $\mathcal{E}$ Public Affairs, 22(2), 146-66.

Rosanvallon, P. (1995). The New Social Question: Rethinking the Welfare State [La Nouvelle Question Sociale. Repenser l'Etat-providence]. Seuil.

Stavem, F. P., \& Støren, B. N. (2016). Fairness and inequality: Measuring fairness preferences and identifying the unfair income inequality in germany [M.Sc. Thesis]. https://openaccess.nhh.no/nhh-xmlui/handle/11250/2404806. 